\title{
Perception of academic nursing staff toward shared governance
}

\author{
Raghad Abdelkader, Mahmoud Ogla Al-Hussami, Marwa Al barmawi, Ali Saleh, Thana A. Shath \\ Faculty of Nursing, University of Jordan, Amman, Jordan
}

Correspondence: Mahmoud Al-Hussami. Address: Faculty of Nursing, University of Jordan, Amman 11942, Jordan. Telephone: 96-265-355-000 ext. 23138. Email: m.alhussami@jo.edu.jo

Received: December 11, 2011

DOI : $10.5430 /$ jnep.v2n3p46
Accepted: January 10, $2012 \quad$ Published: August 1, 2012

URL: http://dx.doi.org/10.5430/jnep.v2n3p46

\section{Abstract}

Shared governance is the set of practices under which faculty members and other staff participates in the decision-making process concerning the operation of their institution and may interfere with the everyday work and activities. The perception of academic nursing staff toward "shared governance" was assessed in a nonexperimental survey research design. Using a nonprobability sampling method, all academic nursing staff had the opportunity to respond to the Collaborative Behavior Scale (CBS) at the pre-implementation of shared governance model. Four universities, including public and private universities were included in the study. Both surveys contained a short demographic section and the Collaborative Behavior Scale CBS adapted from Stickler 1991. Results showed a low level of perception which presented by the collaborative behaviors toward shared governance. Interestingly, commitment to shared governance was neither sufficient nor satisfied during this time. Long experiences with advanced ages for MSc and PhD holders' had significantly higher scores on perception than other groups. The results of the survey indicated that academic staff members recognized shared governance as a process, not a project, and that it takes time to share responsibility, accountability, and authority for faculty members. Overall, Jordanian academic nursing staff have not enough willingness nor commitment to shared governance principles.

\section{Key words}

Academic staff, Empowerment, Shared governance

\section{Background and significance}

Shared Governance (SG) is a set of practices under which faculty members and other staff within a given college participate in the decision-making process; especially the decisions concerning the operation of their institution and may interfere with the everyday work and activities ${ }^{[1,2]}$. The process of sharing decisions and authority can be seen as a privilege or a right that supports the modern administrative models ${ }^{[3]}$. Part of the philosophy of SG is based on the concept of decentralized management, which provides faculty with autonomy and enriches the sense of empowerment ${ }^{[4]}$. Furthermore, it rests on the assumption that faculty should take a fundamental role in decision-making and be part of the planning process ${ }^{[5]}$.

The process of improving administrative outcomes while improving the other components of any faculty or institute has been in the eyes and minds of many specialists in the field. Upenieks ${ }^{[6]}$ reported that managerial concepts that enhance 
quality management propose that work environment within any organization needs to value quality, empower the staff, and emphasize leadership and team work. These are all found to be congruent with the application of SG. In addition, Porter-O'Grady ${ }^{[7]}$ believes that SG has its roots in the critical social theory, which has its impact on the formulation of a considerable parts of the nursing profession philosophy.

While SG was viewed as a form of participative management Porter-O'Grady ${ }^{[8]}$, the pioneer in the study of SG, stated that this concept differs from participative management, whereas the former implies that others are allowed to participate in decision making over which someone has control. Meanwhile the decision making in SG is, in fact, the responsibility of all members in the group. Furthermore, it is accountability-based approach that may change the locus of control according to accountability and the legitimate location of authority for allowing more independence and productive oriented $\operatorname{approach}^{[4]}$.

Although a number of advantages were reported in literature related to the when faculty members' participation in SG, several challenges also exist. Implementation of SG can be very stressful when abandoning essential issues concerning its nature compared with the traditional forms or models of governance usually adopted in any institute, especially the academic ones. The most obvious challenge involves modifying the structure of the organization, reframing the manager role for the empowerment environment, and resistance to change historical patterns of bureaucracy ${ }^{[8]}$.

Generally, broad participation in decision-making increases the level of employee engagement in the institution and promotes its success ${ }^{[9]}$. As a result, shared decision-making can be viewed as a key strategy to improve productivity, enhance satisfaction, and improve retention in all kinds of organizations ${ }^{[10,11]}$.

In Jordan the Faculties of Nursing has a bureaucratic structure which reflects a parent-child system of interaction and communication between managers and staff; also this structure reflects a vertical notion of power, interaction and authority, and often leads to conflict. However, the faculty members who actually deliver teaching and care to students often absent from policy-making processes and the staff had little power and authority within this rigid formal hierarchical bureaucracy structure. So, implementing shared governance emerged as one way to give these faculty members equal footing with managers to allow them to participate in decision -making processes that affect their practice and will surface a radical break from traditional governance where the staff had little power to managerial innovation governance that legitimizes staff control over practice. The purpose of this study was to describe the perception of academic nursing faculty members toward principles of shared governance at public and private universities in Jordan.

\section{Methods}

\subsection{Research questions}

What are the perceptions of academic nursing staff regarding shared governance principles at Jordanian Universities? Are there any statistically significant differences between academic nursing staff's perceptions regarding the presence of shared governance principles in their faculties based on gender, academic degree, age, years of experience, and type of university?

\subsection{Study design}

A self-reported cross-sectional survey design was used to collect data from academic nursing staffs who were teaching nursing students between June 2011 and October 2011. The cross-sectional survey method was used to gather data from a large number of participants and the use of a questionnaire eliminates the effect of a researcher on participants which allows them more freedom to answer the questions honestly and openly. 


\subsection{Population and sampling}

There are nine universities with nursing programs in Jordan, five of them are public and the others are private. All academic nursing staffs currently working at the nursing programs (doctoral in nursing philosophy, master programs in clinical nursing, maternal-child nursing, palliative, and psychiatric nursing care, and Baccalaureate program) within Jordanian Universities around 300 staff were eligible candidates to participate in this study. Doctorate and Master degree faculty are required to participate in all aspects of university life-teaching, scholarship, and services. Bachelor holders are considered clinical instructors. So participants included members of doctoral holders (PhD), master degree holders (MSN) and bachelor holders (BSN), regardless whether they working in any nursing departments, either Clinical Nursing, Maternal and Child Health, or Community and Psychiatric Health Department. Four schools were randomly selected included two public and two private universities with around total staff of 140 members. Using a nonprobability, convenience sample, all academic staff members had the opportunity to participate in the Shared Governance Survey between June 2011 and October 2011.

\subsection{The instrument}

The Collaborative Behaviors Scale (CBS) was used in this study. It was developed by Stichler ${ }^{[12]}$ to measure respondents' perceptions of collaborative behaviors and the effects of collaborative in predicting job satisfaction and anticipating turnover with an estimated Cronbach's alpha $0.80^{[13]}$. This tool includes 20 items which specifies the level of teamwork partnership, affiliation and collaboration in shared decision-making by faculty and managers. Each item has four responses ( 1 = rarely, 2 = sometimes, 3 = often, and 4 = nearly always). The overall score for the scale is 80 with a cutoff point 50 . Scores below 50 indicates lack of collaboration between the faculty and the managers.

\subsection{Protection of human subjects}

Ethical approval was sought and granted by the Research and Ethics Committee at Faculty of Nursing/ University of Jordan and by the research and Ethics Committee at each administration departments of university that took part in the study. Participation was voluntary and personal identity was kept anonymous. Furthermore, detailed information about the objectives of the study was contained through the questionnaire and if the academic staff agreed to participate returned questionnaire implied consent.

\subsection{The procedure}

Questionnaires were distributed to nursing schools in the four universities. A list of an estimated number of available academic staff was prepared from the selected universities one day before data collection. At the time of data collection, questionnaires were distributed and handed to them by the researchers. Each questionnaire had a cover letter explaining the nature of the study, aims, and way of completion and return. Self-completed questionnaires were then handed over together in an envelope to the researchers.

\subsection{Analysis}

All statistical procedures was performed using Statistical Package for the Social Sciences (SPSS Inc., Chicago, II, USA) and produced at $\dot{\alpha}=0.05$ significance level (2-tailed). Descriptive statistics was used to describe the mean, frequency, percentage for each item of Collaborative Behaviors Scale. One-way ANOVA and independent $t$-test were used to differentiate between groups' perception (gender, degree of education, type of university and experiences) to shared governance.

\section{Results}

Of the 120 questionnaires distributed, 95 were valid for analysis (Response Rate=79\%). The majority of participants were $\mathrm{PhD}$ holder (41.8 \%), 38.9 \% MSN, and $20 \%$ BSN holders. As expected more than half of the sample were female 
(65.3\%) with a mean age 42 years. Around half of the sample (46.3\%) was derived from the clinical nursing department and the other half from both maternal-child health, and community department 30.5\%, 23.2\% (respectively). The collaborative behavior scores were varied from 32-77 out of 80 . The mean score was 50.4 which indicated low level of collaborative behaviors that reflected the shared decisions among the faculty members.

Results revealed limited collaboration between the academic staff and their managers as shown in Table 1 . Only $11.6 \%$ of them were nearly always committed to working together as a team, $51.6 \%$ reported that they sometimes acknowledge one another's competence, half of them (50.5 \%) were sometimes supported each other as team members. Just 10.5\% trusted one another.

For developing shared governance principles, unexpectedly, around half of them (45.3\%) reported that sometimes they work together as a team and $7.4 \%-10.3 \%$ of them always make an effort to resolve any conflict. On the other hand, there were some commitments from the academic staff to work together in order to meet the individual or institutional goals; 51.6\% participate actively in the relationship to meet their institutional goals (see Table 1).

Table 1. Collaboration between the Academic Staff and their Managers

\begin{tabular}{|c|c|c|c|c|}
\hline Items & Rarely \% & Sometime\% & Often \% & Nearly always \% \\
\hline 1. We feel free to share idea with one another & 10.5 & 42.1 & 41.1 & 6.3 \\
\hline 2. We acknowledge one another's competence & 8.4 & 51.6 & 35.8 & 4.2 \\
\hline 3. We support each other as team members & 4.2 & 50.5 & 37.9 & 7.4 \\
\hline 4. We work as partners & 8.4 & 47.4 & 31.6 & 12.6 \\
\hline 5. We are committed to working together as a team & 7.4 & 47.4 & 33.7 & 11.6 \\
\hline 6. We trust one another & 8.4 & 51.6 & 29.5 & 10.5 \\
\hline 7. There is a sharing of expertise and talents between us & 6.3 & 46.3 & 37.9 & 9.5 \\
\hline 8. My opinion are listened to & 8.4 & 32.6 & 48.4 & 10.5 \\
\hline $\begin{array}{l}\text { 9. We work as equals or partners for the accomplishment of same } \\
\text { goals }\end{array}$ & 10.5 & 38.9 & 42.1 & 8.4 \\
\hline 10. I feel that my input is truly valued & 8.4 & 46.3 & 37.9 & 7.4 \\
\hline 11. We work together as a team & 8.4 & 45.3 & 34.7 & 11.6 \\
\hline 12. We work together as associates & 5.3 & 44.2 & 41.1 & 9.5 \\
\hline 13. There is a feeling of mutual regard and respect & 8.4 & 33.7 & 43.2 & 14.7 \\
\hline 14. We make an effort to resolve any conflict & 4.2 & 37.9 & 50.5 & 7.4 \\
\hline $\begin{array}{l}\text { 15. We actively participate in the relationship to meet our } \\
\text { institutional goals }\end{array}$ & 2.1 & 38.9 & 51.6 & 7.4 \\
\hline 16. We share information openly with one another & 4.2 & 46.3 & 35.8 & 13.7 \\
\hline 17. We solve problems together & 7.4 & 44.2 & 37.9 & 10.5 \\
\hline $\begin{array}{l}\text { 18. We recognize our independence with one another to meet our } \\
\text { goals }\end{array}$ & 3.2 & 42.1 & 49.5 & 5.3 \\
\hline $\begin{array}{l}\text { 19. We recognize the need to have a sense "give and take" in the } \\
\text { relationship }\end{array}$ & 10.5 & 31.6 & 51.6 & 6.3 \\
\hline $\begin{array}{l}\text { 20. We are committed to the process of working together to the } \\
\text { accomplishment of same goals }\end{array}$ & 6.3 & 41.1 & 42.1 & 10.5 \\
\hline
\end{tabular}

There was no statistically significant differences found between academic nursing staff's' perceptions which presented by collaborative behavior scores regarding the presence of shared governance principles in their faculties based on gender ( $t=0.44$ (93), $P=0.663$ ). While, there were statistical significance differences found between academic nursing staff's' perception and the academic degree $(\mathrm{F}(1,2)=7.65, \mathrm{~d} f: 2, P=0.001)$.

The analysis of variance (ANOVA) test revealed that there were differences between groups' means. A large difference between BSN (n:19, M = 43.68, SD:7.4, CI:95\%, LL:40.11, UL:47.25) and MSN (n:37, M = 51.24, SD:9.7, CI:95\%, 
LL:48.00,UL:54.48) at Post Hoc: LSD $P=0.003$, and PhD (n:39, M = 52.9, SD: 8.00 CI 95\%, LL:50.34, UL: 55.55) at $P<0.001$, while there was not significance difference between $\mathrm{MSN}$ and $\mathrm{PhD} P=0.391$ (see Figure 1).

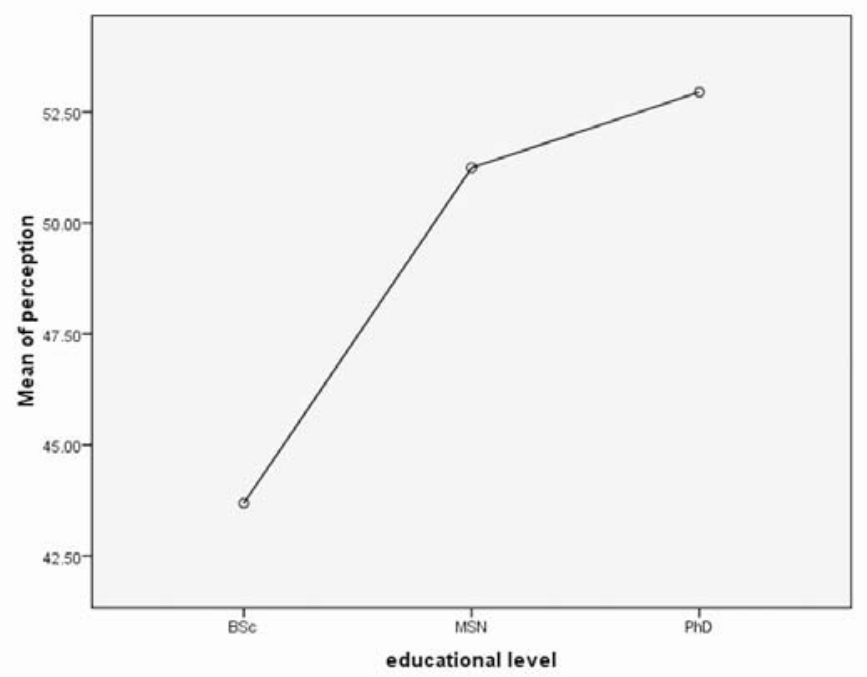

Figure 1. Mean of collaborative behavior and educational level

On the other hand, there were statistical significance differences found between academic nursing staff's' perception and their ages (20-30, 31-40, 41-50 and 51-60). Analysis of variance (ANOVA) test revealed that there were differences between groups means at $(\mathrm{F}(1,3)=3.47, \mathrm{~d} f: 3, P=0.019)$ as follow: a large difference between age of 20-30 years (n:21, $\mathrm{M}$ = 45.5, SD:10.3, CI:95\% LL:40.8.11,UL: 50.25) compared with age of 41-50 years (n:35, M=52.3, SD:6.9, CI:95\% LL:49.9, UL:54.7) by Post Hoc LDS $P=0.006$, and age of 51-60 years (n:9, M =54.9,SD: 9.9, CI: 95\% LL:48.6., UL: 52.3) at $\mathrm{P}=.009$. While there was no significance difference between age of 20-30 $\mathrm{M}=45.5$ and 31-40 years ( $\mathrm{n}: 30$, $\mathrm{M=52.9}$ at $P=$.056)(see Figure 2). The comparison between governmental and nongovernmental universities by independent samples $\mathrm{t}$ test revealed that there was no statistical significance found between them (n:(72,23), M:49.69, SD: 9.0,M:52.52, SD:9.5 respectively) at $t(2,93)=-1.25 \mathrm{CI}: 95 \%, \mathrm{LL}-7.12, \mathrm{UL}: 1.6$, at $P=0.213$.

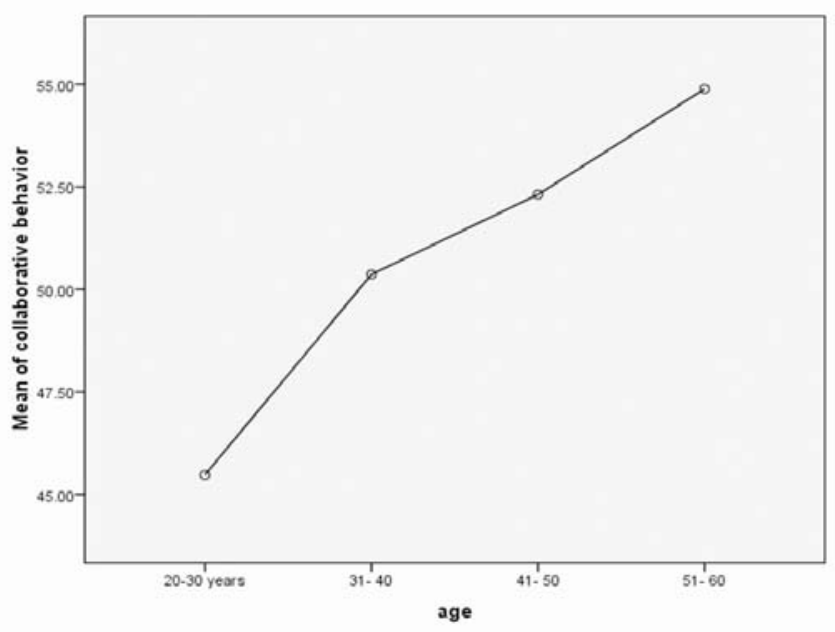

Figure 2. Collaborative behavior and academic nursing staffs’ ages 
However, there was positive correlation between academic nursing staff's' perceptions regarding the presence of shared governance principles in their faculties and years of experience (Pearson $r=0.23, P=0.024, \alpha<0.05$ ). Academic nursing staff's' perceptions has also moderate positive correlation with increasing the age (Pearson $r=0.31, P=0.002, \alpha<0.001$ ).

\section{Discussions}

Nursing faculties in Jordan started to work toward organizational commitment to achieve their goals. This is congruent with shared governance principles. SG is best demonstrated when the faculties, as a whole, is committed to a common vision of the academic nursing mission. Because participants in the shared governance process will be empowered with the responsibility to make decisions that affect the college as a whole, they will operate in a consensus-building fashion where open communication and accountability are paramount ${ }^{[14]}$. Meanwhile Jordanian academic nursing staffs either males or females need to raise their awareness about the essential principles for SG as sharing in resolve conflict and solve problems within team spirit even when there are barriers and challenges.

Findings described how Jordanian academic nursing staffs' perceptions toward SG are still not mature enough to implement SG models. Designing, implementing, and evaluating a shared governance program is a difficult task ${ }^{[15]}$. However, the change to a shared governance model requires a shift in perception and is an ongoing process ${ }^{[15,16]}$. Jordanian academic nursing staff need to shift as follows: (a) practice decisions would continue to come from management, especially that most of managers now in faculties are $\mathrm{PhD}$ holders who have highly significant of collaborative behavior; (b) academic staff nurses would not be released from their duties as lectures or students' training to attend meetings. However, the study finding related to changing the behavior and attitudes of academic nursing staff toward their role is usually unclear and this is supported by Anthony ${ }^{[15]}$ discussion about the change process to SG. Moreover, SG utilizes the collective intelligence of the nursing faculty in planning and decision-making and involves joint effort in the development of faculty policy. This process fosters a shared confidence that extended to all other areas of responsibility within the faculty, e.g., departments, programs, and units ${ }^{[10]}$.

Several issues related to barriers to shared governance were determined based on academic nursing staff's perception of SG. The most commonly cited reasons for difficulty with shared governance were lack of concern to shared governance (lack of interest in putting in more work than their basic duties, insufficient incentives, and spending extra time for meetings) and uneven outcomes of shared governance (some of them were dealing with nursing teaching issues while others were dealing with unimportant issues). Contributing to these two overriding barriers was insufficient time out of staffing for shared governance, problems with communication, and lack of clarity or education regarding roles and responsibilities of SG. The findings from this study supported by Richards et al. ${ }^{[17]}$ who found different barriers for SG implementation including role ambiguity and lack of communication with staff members working in different departments.

Even though there is a positive correlation between perception and educational level ( $\mathrm{PhD}$ holders), but still all the faculty members even $\mathrm{PhD}$ holders have low level of knowledge regarding the basic principles of shared governance. Moreover, findings discovered that the state of dissatisfaction among faculty members is expected to lead to turnover and shortage. To overcome this problem, faculty members must feel that they are part of the system and have input and positive contribution in its activities and outcomes. This can be achieved by introducing shared governance to the Faculty of Nursing environment.

Although there is evidence in the literature that shared governance is associated with positive organizational outcomes, there is little evidence in the literature to describe the best practice of implementing shared governance ${ }^{[18]}$. More research need to be conducted to determine how to prepare managers to resign some power while supporting the efforts of shared governance councils. However, the more critical need is to conduct research to determine how to prepare shared Published by Sciedu Press 
governance council chairs and members to assume new roles. The most important recommendation for preparing the Jordanian nursing faculty is to establish a multi-stakeholder body to coordinate the implementation of shared governance. The second recommendation concerns the faculty members themselves working on introducing change within their institutions using collective bargaining. The strongest SG systems are based on sound collective bargaining contracts that clearly delineate an active role for faculty at the institution. Specifically, collective bargaining may strengthen collegiality by establishing and enforcing contractual ground rules supporting it. This could be emphasized by rules mandated by law-makers regarding nursing programs, in specific, or may even extend to include other specializations. The third major recommendation is to enhance organizational communication through providing accessible and transparent information in a way that invites constructive feedback and engagement.

\section{Conclusions}

This cross-sectional study assessed the perception of academic nursing staffs toward shared governance principles in Jordanian nursing schools. The findings demonstrated that the academic nursing staffs are still not ready and need preparation before implementing the shared governance model. The results of this assessment show that the managers and some faculty members who are in the management system are perceived to be the decision makers related to most activities in their schools.

\section{References}

[1] Blount K, Krajewski AM, Alminde C, Swift S, Green M, Sullivan S. Shared governance: Early payoffs from leadership and staff engagement. Nurse Leader. 2007; 5(5):38-54. http://dx.doi.org/10.1016/j.mnl.2007.07.003

[2] Roach EJ. Shared governance in nursing. The Nursing Journal of India. 2009; 100(4): 76-78. PMid:20527491

[3] Fontaine DK, Stotts NA, Saxe J, Scott M. Shared faculty governance: A decision-making framework for evaluating the DNP. Nursing Outlook. 2008; 56(4): 167-173. PMid:18675017 http://dx.doi.org/10.1016/j.outlook.2008.02.008

[4] Zungolo EH. Nursing and academic mergers of the health sciences: A critique. Nursing Outlook. 2003; 51(2): 52-58. http://dx.doi.org/10.1016/S0029-6554(02)05452-0

[5] Zuzelo P, McGoldrick TB, Seminara P, Karbach H. Shared governance and EBP: A logical partnership? Nursing Management. 2006; 37(6): 45-50.

[6] Upenieks VV. What constitutes effective leadership? Perceptions of magnet and nonmagnet nurse leaders. Journal of Nursing Administration. 2003; 33(9): 456-467. http://dx.doi.org/10.1097/00005110-200309000-00006

[7] Porter-O'Grady T. A different age for leadership, part 1: New context, new content. Journal of Nursing Administration. 2003; 33(2): 105-110. http://dx.doi.org/10.1097/00005110-200302000-00007

[8] Porter-O'Grady T. Implementing shared governance: Creating a professional organization. St. Louis: Mosby Year Book; 1992.

[9] Brown WO. Faculty participation in university governance and the effects on university performance. Journal of Economic Behavior \& Organization. 2001; 44(2): 129-143. http://dx.doi.org/10.1016/S0167-2681(00)00136-0

[10] Beckwith EG, Silverstone S, Bean D. Creating a culture of academic assessment and excellence via shared governance. Contemporary Issues in Education Research. 2010; 3(2): 35-48.

[11] Gaff JG. What if the faculties really do assume responsibility for the educational program? Liberal Education. 2007; 93(4): 6-13.

[12] Stichler JF. The effect of collaboration, organizational climate, and job stress on job satisfaction and anticipated turnover in nursing. Ann Arbor, MI: University Microfilms, Inc.1991.

[13] Ushiro R. Nurse-Physician Collaboration Scale: Development and psychometric testing. Journal of Advanced Nursing. 2009; 65(7): 1497-1508. PMid:19635097 http://dx.doi.org/10.1111/j.1365-2648.2009.05011.x

[14] Dunbar B, Park B, Berger-Wesley M, et al. Shared governance. Making the transition in practice and perception. Journal of Nursing Administration. 2007; 37(4): 177-183. PMid:17415104 http://dx.doi.org/10.1097/01.NNA.0000266847.84802.ea

[15] Anthony MK. Shared governance models: The theory, practice, and evidence. Online Journal of Issues In Nursing. 2004; 9(1). Available from: http://nursingworld.org/MainMenuCategories/ANAMarketplace/ANAPeriodicals/OJIN/TableofContents/Volume92004/No1Jan 04/SharedGovernanceModels.html 
[16] Hess RG. From bedside to boardroom -- nursing shared governance. Online Journal of Issues in Nursing. 2004; 9(1). Available from:

http://nursingworld.org/MainMenuCategories/ANAMarketplace/ANAPeriodicals/OJIN/TableofContents/Volume92004/No1Jan 04/FromBedsidetoBoardroom.html

[17] Richards KC, Ragland P, Zehler J, et al. Implementing a councilor model: Process and outcomes. Journal of Nursing Administration. 1999; 29(7/8): 19-27. http://dx.doi.org/10.1097/00005110-199907000-00009

[18] Edwards M, Jabs LB. When safety culture backfires: Unintended consequences of half-shared governance in a high tech workplace. Social Science Journal. 2009; 46(4): 707-723. http://dx.doi.org/10.1016/j.soscij.2009.05.007 